\title{
Informações, actualidade
}

\section{Louis de Broglie (1892-1987)}

Com o falecimento recente do Professor Louis de Broglie desapareceu o último dos grandes físicos desta inclita geração que, há já mais de meio século, revolucionou irreversivelmente as nossas concepçðes sobre a estrutura da matéria. E, para prestar a devida homenagem à sua memória, há que recordar aqui o essencial da sua bibliografia científica.

Nascido numa velha família de alta nobreza, o príncipe de Broglie concluiu os seus estudos secundários em 1907, simultaneamente em Matemática e Filosofia. No ano seguinte, já licenciado em História, iniciou estudos de Direito, mas os problemas físicos e filosóficos levantados pela descoberta da teoria da Relatividade e pelo advento da constante quântica atraíram-no a tal ponto que decidiu mudar de rota e licenciar-se em Física (1911-13). Seria doravante um físico, embora as marcas da sua formação inicial permanecessem no interesse profundo que sempre manifestou pela História e pela Filosofia das Ciências.

Mobilizado em 1914 como radio-electricista, ocupar-se-ia durante os anos da 1. ${ }^{a}$ Grande Guerra dos problemas técnicos, então ainda na infância, levantados pelas telecomunicaçðes. Foi decerto uma experiência pessoal enriquecedora porque, muitas décadas mais tarde, mantinha-se bem informado de tudo quanto ocorria nesse domínio, aparentemente tão distante das suas preocupaçø̃es científicas. Em todo o caso, só em 1919 é que Louis de Broglie ficou novamente disponível para retomar a sua meditação sobre o problema dos quanta. Frequentava então assiduamente o laboratório de Maurice de Broglie, seu irmão mais velho, onde se investigavam sobretudo as propriedades corpusculares dos raios X. Mas no meio desse grupo de brilhantes experimentadores ele permanecia solitário, fascinado por questð̋es mais gerais de índole teórica: como entender os sucessos da teoria atómica de Bohr-Sommerfeld, construção híbrida onde se sobrepunham às leis da Física Clássica regras arbitrárias de quantificação que as contradiziam?

Só nos começos de 1923 é que Louis de Broglie encontrou resposta às questðes que tanto o preocupavam. Em três Notas apresentadas nesse ano à Academia das Ciências de Paris pretendia ele que as estranhas propriedades dos edifícios atómicos, essas discontinuidades manifestadas pela necessidade de introduzir números inteiros na descrição do seu comportamento, eram uma mera consequência de a matéria, tal como a luz, também possuir propriedades ondulatórias. Apoiando-se sobretudo na Relatividade einsteiniana, que conhecia profundamente, de Broglie deduzira desta ideia inverosímel consequências precisas que hoje se tornaram clássicas, nomeadamente a fórmula $\lambda=\mathrm{h} / \mathrm{p}$, a identificação do princípio de Fermat em Óptica com o princípio de Maupertuis em Mecânica ou a demonstração de que a uniformidade das ondas de matéria implicava a validade do postulado de quantificação dos estados estacionários.

Sob uma forma mais acabada, estes resultados foram apresentados como tese de doutoramento, submetida à aprovação prévia de Paul Langevin, que era na época um dos mais conceituados especialistas franceses quer em Relatividade, quer em teorias quânticas. Mas as ideias de base deste trabalho eram tão inovadoras que o próprio Langevin o considerou "extravagante"; teve porém a prudência de o enviar ao seu amigo Eistein o qual, entusiasmado, foi de opinião que de Broglie "tinha levantado uma ponta do grande véu”. E, assim, a tese pôde ser brilhantemente defendida, em Novembro de 1924, perante um júri presidido por Jean Perrin e no qual participavam Elie Cartan e Charles Mauguin, além do próprio Langevin como membro convidado. Embora todos os membros do júri tivessem considerado essa tese de uma originalidade excepcional - era difícil dizer menos - todos eles confessariam mais tarde o seu cepticismo quanto à realidade física dessas "ondas de matéria" as quais, segundo de Broglie, seriam certamente detectáveis por experiências do tipo clássico, como as interferências ou a difracção. E nem foi preciso esperar três anos para que Davidson e Germer, fazendo incidir um feixe de electrðes lentos sobre um cristal de níquel, verificassem a existência das con-

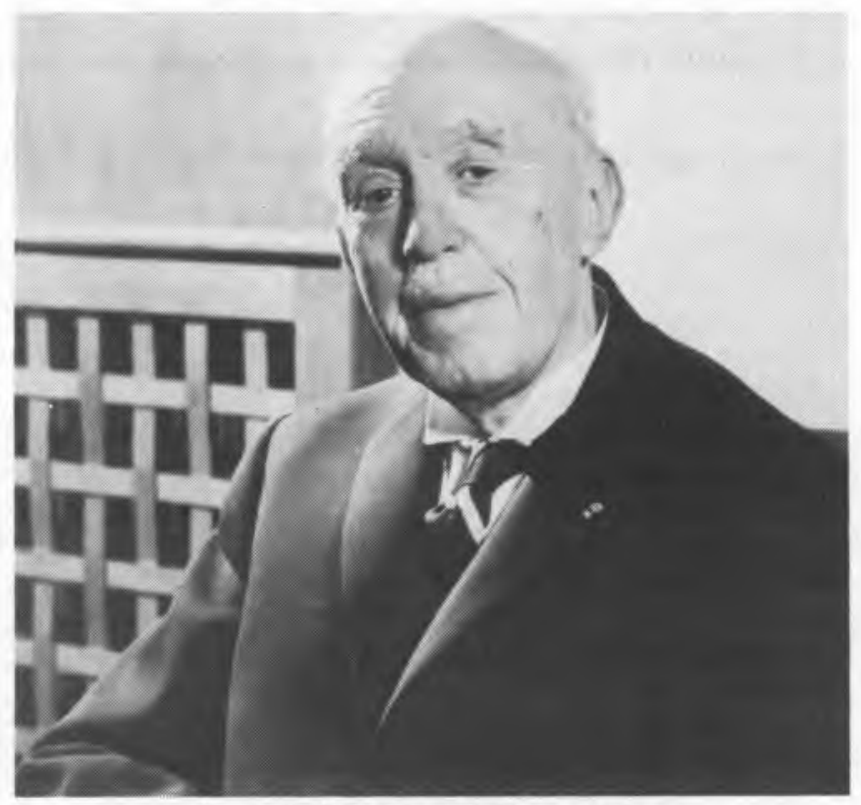

Louis de Broglie em 1970 aos 78 anos 
troversas ondas broglianas. De há muito aprendemos a reproduzir com elas todos os fenómenos característicos das ondas electromagnéticas, o que significa que há razởes idênticas para crer na existência de ambas elas. E a microscopia electrónica, com a sua formidável gama de aplicaçð̃es científicas e técnicas, está aí para nos recordar as consequências que podem ter as puras especulaçōes de um teórico. O prémio Nobel que de Broglie recebeu em 1929 era o reconhecimento do valor da sua obra.

Entretanto, em 1926, Schrödinger eliminara a principal lacuna de que padecia a teoria de de Broglie, descobrindo a equação não relativista que governa as ondas de matéria; Pauli generalizou-a, logo a seguir, introduzindo-lhe o spin, enquanto outros (entre os quais o próprio de Broglie) a transcreviam no quadro relativista, abrindo o caminho para que Dirac, numa espécie de operação de magia lógica, obtivesse as famosas equaçðes relativistas da partícula de spin $1 / 2$. O formalismo quântico avançava de vento em popa e não havia dúvidas quanto à natureza estatística das previsőes dele resultantes mas o desacordo era flagrante sobre a maneira como convinha interpretar essas leis probabilisticas.

Tentando preservar a inteligibilidade do mundo físico, de Broglie tentara conceber um modelo de partícula que fosse, simultaneamente, corpúsculo e onda e, por isso mesmo, susceptível de ser descrita no quadro do espaço e do tempo; as leis probabilísticas da Microfísica seriam, assim, a manifestação de uma causalidade subjacente, $e$ as relaçðes de Heisenberg traduziriam apenas as irremediáveis limitaçøes do observador sobre a dinâmica dos sistemas quânticos. Era uma teoria muito ambiciosa e cujo desenvolvimento comportava sérios problemas matemáticos de modo que, quando o grande afrontamento ocorreu, na V Conferência Solvay realizada em Outubro de 1927, de Broglie só podia apresentar as suas teses sob uma forma ainda incipiente. Contra ele, e Einstein, e Schrödinger e o velho Planck, uma coorte brilhante e bem organizada incluindo Bohr, Born, Heisenberg, Dirac e Pauli fez prevalecer a interpretação da Mecânica quântica de epistemologia positivista que se tornou paradigmática: as leis de probabilidades como limite definitivo do conhecimento possivel, as relaçð̄es de Heisenberg exprimiam um indeterminismo essencial, os micro-objectos era estranhos seres proteiformes que, consoante as circuntâncias, se apresentavam ora como ondas ora como corpúsculos.

De Broglie resignou-se então a adoptar o ponto de vista maioritário, porque estava ciente das dificuldades a vencer no desenvolvimento das suas ideias mas também porque tinha outros projectos de trabalho que o interessavam muito. $\mathrm{Na}$ verdade, parecia-lhe inaceitável que, estando a teoria dos fotð̌es na origem do problema do dualismo onda-corpúsculo, ninguém estivesse preocupado em inserir o fotão no quadro conceptual da Mecânica quântica. Para o conseguir, foi levado a "fundir" matematicamente duas equaçð̄es de Dirac (duas partículas de spin 1/2) esperando assim obter simultaneamente a descrição de uma partícula de spin 0 e outra de spin 1; as equaçס̄es que obteve para as partículas de spin 1 (como o fotão) revelam-se quase miraculosas pois, escritas em termos vectoriais, reproduziam as equaçð̋es clássicas de Maxwell só acrescidas de uns tantos termos que se anulam com a massa da partícula. Todo o Electromagnetismo se integrava no formalismo quântico graças a esta Mecânica ondulatória do fotão, cujo desenvolvimento ulterior deu aso a uma Teoria geral das partículas com spin.

Não farei aqui qualquer referência aos numerosos trabalhos publicados por de Broglie como, por exemplo, a óptica electrónica, a Termodinâmica relativista, a teoria dos guias de onda ou o campo subtrativo, pois interessa sobretudo assinalar a grande viragem sofrida pela sua carreira científica no começo dos anos cinquenta. Tendo procedido a uma análise crítica exaustiva dos fundamentos da Mecânica quântica, concluiu que a teoria aceite se revelava insatisfatória, tornando-se pois necessário procurar reconstruí-la noutros moldes. Perante o ceptivismo ou a hostilidade dos seus pares, dos quais só Einstein the endereçou uma palavra de apoio, esse homem coberto de honras ia ousar arriscar o seu prestígio para ser fiel à sua verdade.

A partir daí, de Broglie empreendeu um imenso esforço para desenvolver uma versão diferente da teoria dos quanta, baseada nas ideias que já tinha esboçado em 1927 , e não são aqueles que, como eu, tentaram modestamente apoiá-lo nessa tarefa os mais indicados para fazer um julgamento imparcial dos resultados assim alcançados. Não se poderá, contudo, deixar de reconhecer pelo menos que esta tentativa de de Broglie teve o mérito de desbloquear as investigaçōes sobre um tema importante até aí quase interdito, que a sua "teoria da dupla solução", embora ainda permaneça inacabada, constitui hoje a alternativa mais promissora à formulação ortodoxa, que o problema em causa não é de indole metafísica (como alguns quiseram fazer crer), pois em breve haverá respostas experimentais a questð̋es essenciais no debate. A derradeira fase da obra brogliana, aventura ousada de um espírito corajoso, aguarda o julgamento da historia.

Não quero concluir sem um testemunho pessoal. Louis de Broglie não era somente um cientista de craveira excepcional e de imensa cultura, de quem se podia ouvir, acidentalmente, uma reflexão sobre a sintaxe da língua portuguesa, um comentário sobre a poética de Victor Hugo ou um ensinamento tirado da obra de Newton. Para além de tudo isso, com a sua lendária timidez, a sua aristocrática cortezia, essa estranha ignorância das realidades comezinhas do quotidiano, era um homem de uma profunda e púdica bondade, e os que tiveram o raro previlégio de conviver de perto com ele não veneram apenas a memória de um físico de génio mas também a de um ser profundamente humano.

João Andrade e Silva

Departamento de Fisica, Faculdade de Ciências de Lisboa

\section{Encontro sobre Educação em Ciências}

A área de Metodologias de ensino da Unidade Científico-Pedagógica de Ciências da Educação da Universidade do Minho está a organizar o I Encontro sobre Educação em Ciências: Aspectos actuais do Ensino-aprendizagem das Ciências da Natureza, que decorrerá de 27 a 30 de Maio de 1987.

Este encontro destina-se a 350 professores do ensino: básico, secundário, superios.

Do programa científico constarão conferências, uma mesa-redonda e "workshops" sendo algumas destas últimas 
específicas para determinados níveis de ensino (ver literatura sobre "workshops").

\section{Local}

O levantamento de documentação, a sessão de abertura e as conferências terão lugar no Seminário de Santiago. As "workshops" terão lugar nas instalaçð̃es da U.M., na rua Abade da Loureira, e na Casa da Cultura.

O secretariado do Encontro funcionará no Seminário de Santiago.

\section{Inscrição}

Deverá ser feita através da correspondente ficha a remeter à Comissão Organizadora. $\mathrm{O}$ número de participantes está limitado a 350 pelo que apenas serão aceites as primeiras 350 inscriçðes.

Os preços de inscrição são os seguintes:

Até 15 de Abril - $5000 \$ 00$

Após 15 de Abril - $7000 \$ 00$

A inscrição dá direito de acesso à sessão de abertura, a todas as conferências, a 2 "workshops", à pasta com documentação, à tradução simultânea das conferências em inglês e francês e ao cocktail de abertura.

Confirmar-se-á por correio a inscrição no encontro e nas "workshops".

\section{"Workshops"}

Cada participante tem direito a assistir a 2 "workshops". Estando o número de participantes por "workshop" limitado, a inscrição nas mesmas será efectuada por ordem de entrada da inscrição no Encontro e com base nas preferências indicadas na ficha de inscrição. Recomenda-se a indicação de seis alternativas. Caso as seis alternativas indicadas estejam já preenchidas o participante será inscrito em duas "workshops" que ainda tenham vagas. Não haverá tradução das "workshops" organizadas por especialistas estrangeiros.

\section{Exposições}

Durante o Encontro decorrerá uma exposição de material didáctico, técnico e científico.

A exposição estará aberta nas tardes dos dias 27 a 29 especialmente para aqueles participantes que em cada um destes dias não participarem em "workshops".
Para mais informaçð̃es contactar para:

Comissão Organizadora do I ESEC

Universidade do MInho

R. Abade da Loureira

4700 - Braga

(Tel.: 27768/27776)

\section{Homenagem a Anastácio da Cunha (1744-1787)}

Cumpre-se este ano 0 bicentenário do falecimento de José Anastácio da Cunha. Nascido em Lisboa onde frequentou a escola dos oratorianos, cedo revelou interesse pelo estudo da física e matemática, tendo sido tenente de artilharia em Valença do Minho, Pombal nomeou-o lente de Geometria na Universidade de Coimbra em 1773. $\mathrm{Na}$ "viradeira" antipombalina foi preso pela Inquisição em 1778 "por heterodoxia e leituras perigosas», sujeito a auto da fé e condenado a reclusão na Casa do Oratório, onde redigiu a sua obra prima "Principios Matemáticos». Pina Manique aproveitou-o como pedagogo no Colégio de S. Lucas, na recém criada Real Casa Pia, onde sobreviveu os seis últimos anos da sua vida «nunca mais tendo alegria nem saúde». Leitor e tradutor de autores clássicos e iluministas, foi autor dum «Ensaio sobre os Princípios de Mecânica» e duma notável obra poética, apresentada por Hernâni Cidade como precursora do romantismo.

Não obstante a sua ímpar estatura científica e literária, que o fez ser «um daqueles homens raros que nas naçס̃es cultas costumam aparecer», a sua obra caiu hoje no esquecimento, pelo que se torna imperioso reparar esta injustiça histórica, realçando a sua posição de destaque no século das luzes em Portugal e colocando-o na História da Matemática mundial entre os precursores da reforma do cálculo infinitesimal operada pouco depois da sua morte prematura por Bolzano, Gause, Cauchy, Abel e outros matemáticos do século XIX.

No âmbito duma homenagem nacional a Anastácio da Cunha, entre outras iniciativas a promover, o Departaménto de matemática da Universidade de Lisboa propø̃e a realização, na segunda metade de 1987 , de um colóquio com contribuiçøes nacionais e internacionais sobre a sua vida, obra e época, centrando a tónica na componente científica e seu enquadramento histórico-cultural. 